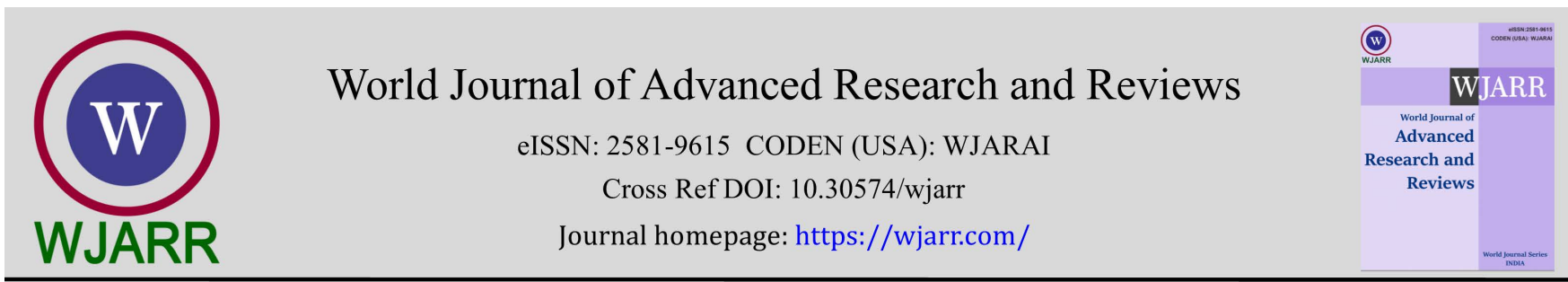

(RESEARCH ARTicle)

\title{
Comparative in-vitro evaluation of two brands of carvedilol uncoated tablets
}

\author{
Vibhavari M. Chatur ${ }^{1,}{ }^{*}$, Sanjay G. Walode ${ }^{1}$, Sheetal V. Patil ${ }^{2}$, Hritik Patwa ${ }^{1}$, Rohit Nalawade ${ }^{1}$ and Anup \\ Nalawade 1
}

${ }^{1}$ Rasiklal M. Dhariwal Institute of Pharmaceutical Education and Research, Chinchwad, Pune, India.

2 PES's Modern College of Pharmacy, Nigadi, Pune, India.

World Journal of Advanced Research and Reviews, 2021, 10(02), 031-038

Publication history: Received on 27 March 2021; revised on 02 May 2021; accepted on 05 May 2021

Article DOI: https://doi.org/10.30574/wjarr.2021.10.2.0190

\begin{abstract}
Comparative study is just a comparison study, according to formal properties, function, purpose and effectiveness. The main purpose of comparative study is, to compare a particular drug of different brands with the help of their stability, efficacy and evaluation parameters. Here we compare the carvedilol drugs different two marketed. It acts as antihypertensive agent so, it mainly preferred for arterial fibrillation, inhibits tachycardia, prevention of stroke, heart failure, it also works by blocking a natural substance like epinephrine, which results to cause lowers the heart rate, blood pressure and strain on the heart. In comparative studies we determined their efficacy and effectivity on the basis of various in-vitro tests like weight variation, friability, hardness, dissolution and disintegration. It can be concluded that standard quality control parameters always should be maintained not only for carvedilol or its combination but also for all kinds of medicine for getting better drug products. The parameters in this comparative study between these two brands showed somewhat variation because every brand have their own method or processing or manufacturing and formulation properties. Mainly these parameters can show the different efficacy and effectivity and made them unique from each other.
\end{abstract}

Keywords: Carvedilol uncoated tablets (3.125mg); In-vitro evaluation; Two available marketed brands.

\section{Introduction}

Carvedilol uncoated tablets $[1,2,3,4,5]$ are generally single layer tablets prepared by a single compression of granules or multi-layer tablets consisting of parallel layers prepared by compression of granules of different compositions. Carvedilol is a lipophilic vasodilating non-cardio selective beta-blocker. It shows sympathomimetic activity. It is metabolized in the liver and rapidly absorbed by oral administration. It blocks norepinephrine binding to alpha-1 adrenergic receptors. This shows reduction in arterial blood pressure, decreasing beta-adrenoreceptor vasoconstrictor tone. It is racemic mixture of ( \pm )-1-(carbazol-4-yloxy)-2-propanol. Carvedilol maintains normal ratio of high-density lipoproteins to low-density lipoproteins. For enhancing aqueous solubility of drugs solid dispersion technique is highly effective. By adding Crospovidone, low concentration of Ac-di-sol, etc. to increase disintegration rate of the tablets. Carvedilol helps to reduces renin release through beta-blockade. Carvedilol is freely soluble in dimethyl sulfoxide, soluble in methanol and methylene chloride, sparingly soluble in $95 \%$ ethanol and isopropanol and partially insoluble in gastric fluid, water and intestinal fluid.

There are many uses of carvedilol such as it is mainly used in hypertension. It shows antioxidant effect. It is also used in the treatment of atherosclerotic disease. It shows reduction of vascular smooth muscle migration. It prevents formation of oxidized low density lipoproteins and vascular smooth muscle inhibition. Carvedilol is used in the treatment of heart failure. Also, it is used to treat Diabetes Mellitus. Carvedilol is used in ischemic heart disease. It is used in patient with

\footnotetext{
* Corresponding author: Vibhavari M.Chatur

Rasiklal M. Dhariwal Institute of Pharmaceutical Education and Research, chinchwad, Pune. 
cirrhosis. Carvedilol is used in patient with ST-segment elevation myocardial infraction treated with primary percutaneous coronary intervention.

Advantages of carvedilol are non-toxic, anti-hypertensive, gives proper therapeutic response, achieved proper therapeutic range in minimal dose, etc. Carvedilol shows multiple side effects such as dizziness, lightheadedness, drowsiness, reduce blood flow, chest pain, dry eyes, etc. Carvedilol is contraindicated in hypersensitivity, chronic obstructive pulmonary disease with bronchial obstruction, patient with severe hepatic dysfunction, severe hypotension, second- or third-degree AV block, patient with metabolic acidosis, etc.

IUPAC Name of Carvedilol: 1-(9H-carbazol-4-yloxy)-3-[2-(2-methoxyphenoxy) ethyl amino] propan-2-ol.

Molecular Formula of Carvedilol: $\mathrm{C}_{24} \mathrm{H}_{26} \mathrm{~N}_{2} \mathrm{O}_{4}$

Molecular Weight of Carvedilol: $406.5 \mathrm{~g} / \mathrm{mol}$.

Structure of Carvedilol:

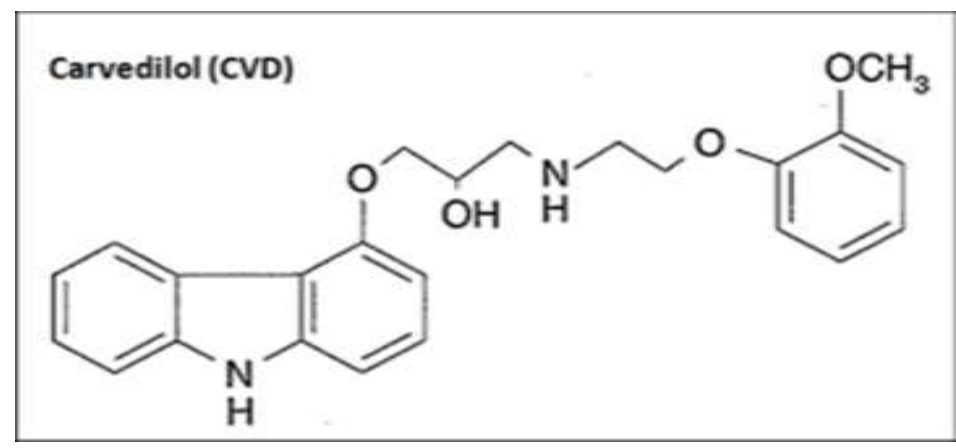

\section{Material and methods}

Comparative in-vitro quality control parameters between the commercially available tablet brands of uncoated Carvedilol in market were studied through the evaluation of weight variation, hardness, friability, disintegration time and dissolution profile. The evaluation was done by performing various test procedures related to the measurement of the quality of tablets.

\subsection{Sample Collection}

To carry out the study, the Carvedilol $3.125 \mathrm{mg}$ uncoated tablets of two different top-level brands were purchased from the drug store. Both the tablet brands of Carvedilol were labelled to contain $3.125 \mathrm{mg}$ of Carvedilol per tablet. After the purchase of the tablets, both the brands were coded as A and B.

\subsection{Chemicals}

Potassium-di-hydrogen phosphate, Sodium hydroxide and Distilled water. All chemicals are used for analytical grade.

\subsection{Equipments}

Monsanto Hardness Tester, Roche Friability Apparatus, U.S.P. II Dissolution Apparatus, Disintegration Apparatus, Analytical Balance, Vernier Caliper.

\subsection{Methods}

For the comparative evaluation, following quality control tests were performed for the tablet brands A and B by referring Indian Pharmacopoeia 2018 to check the in-vitro quality of Carvedilol uncoated tablets.

\subsection{Procedure}

\subsubsection{Dimensional Parameters}

The thickness and diameter of tablets were determined by using the digital Vernier Caliper [8]. 


\subsubsection{Friability Test}

It was performed using Roche Friabilator. 10 tablets were weighed and placed in apparatus. The apparatus was rotated at a speed of $25 \mathrm{rpm}$. The apparatus was made to rotate for $4 \mathrm{~min}$. The tablets were then weighed and the weights were compared with the initial weights. The percentage friability was calculated using the formulas given in following equation. Calculate the \% Friability by following given formula $[6,7,8]$

Where,

$$
\% \text { Friability }=\frac{W_{1}-W_{2}}{W_{1}} \times 100
$$

W1 $=$ initial weight of tablets before rotation

$\mathrm{W} 2=$ final weight of tablets after rotation

\subsubsection{Hardness Test}

The significance of performing hardness test of tablets is to determine the crushing strength of tablets. Hardness of a tablet is defined as the force required to break the tablet. Monsanto Hardness tester, Pfizer hardness tester, Strong Cobb hardness tester, Erweka hardness tester are the different hardness tester apparatus for calculating hardness of the tablet. Place the tablet in between the fixed jaw and moving jaw of the apparatus. By means of screw job, the pressure is applied on the tablets and moving jaw is moved. The point at which the tablet gets broken down, the reading is measured by means of scale. Take 5 readings for accurate and precise result and calculate the mean of 5 readings. Unit of hardness is $\mathrm{Kg} / \mathrm{cm} 2[8,9,10]$

\subsubsection{Weight Variation Test}

The weight variation is done by comparing the individual weight of the tablet to the average weight of the tablets. For weight variation test 20 tablets are needed. The average weight of 20 tablets were weighed and then it was compared with individual tablet weight. The weight variation is expressed in $\%[8,11]$

$$
\% \text { Weight variation }=\frac{W_{1}-W_{2}}{W_{1}} \times 100
$$

Where, $\mathrm{W} 1$ = individual weight of tablet, $\mathrm{W} 2=$ average weight of tablets

Table 1 Weight Variation Limits

\begin{tabular}{|c|c|}
\hline IP/BP & Limit[tablet] \\
\hline $80 \mathrm{mg}$ or Less & \pm 10 \\
\hline $80-250 \mathrm{mg}$ & \pm 7.5 \\
\hline $250 \mathrm{mg}$ or More & \pm 5 \\
\hline
\end{tabular}

\subsection{Disintegration}

It was performed using USP disintegration device. Six tablets were placed in Disintegration test apparatus. It was maintained at $37 \pm 0.2 \mathrm{C}^{\circ} \mathrm{C}$ containing distilled water. The time taken for a tablet to disintegrate was noted down. Time should be recorded after the complete breakdown of the tablet $[8,11]$.

\subsection{Dissolution}

Dissolution is an evaluation parameter in which we determine the time required to dissolve tablet in a particular solvent in in-vitro manner. For dissolution purpose here U.S.P II Dissolution apparatus used with gastric buffer pH 1.3 dissolution medium in which drug is completely soluble. During the process discard the few $\mathrm{ml}$ samples from medium in specific time interval, such as 5, 10, 15, 20 min etc. Those discarded medium absorbance check under UV at specific wavelength $242 \mathrm{~nm}$ and determine the percent release of drug in a graphical manner. $[9,13,14,15]$ 
Table 2 Dissolution parameter

\begin{tabular}{|c|c|c|}
\hline Sr. No. & Parameters & Specifications \\
\hline 1. & Apparatus & $\begin{array}{c}\text { U.S.P. II Dissolution Apparatus } \\
\text { (Paddle type) }\end{array}$ \\
\hline 2. & Dissolution medium & $\begin{array}{c}\text { Gastric Buffer pH 1.3, USP II, } \\
50 \mathrm{rpm}, 900 \mathrm{ml}\end{array}$ \\
\hline 3. & Volume of medium & $900 \mathrm{ml}$ \\
\hline 4. & Temperature & $37 \pm 0.5{ }^{\circ} \mathrm{C}$ \\
\hline 5. & Discarded volume & $10 \mathrm{ml}$ \\
\hline 6. & Speed of paddle rotation & $50 \mathrm{RPM}$ \\
\hline 7. & Time interval of sampling & $5 \mathrm{minutes}$ \\
\hline 8. & Absorbance detection wavelength & $242 \mathrm{~nm}$ \\
\hline
\end{tabular}

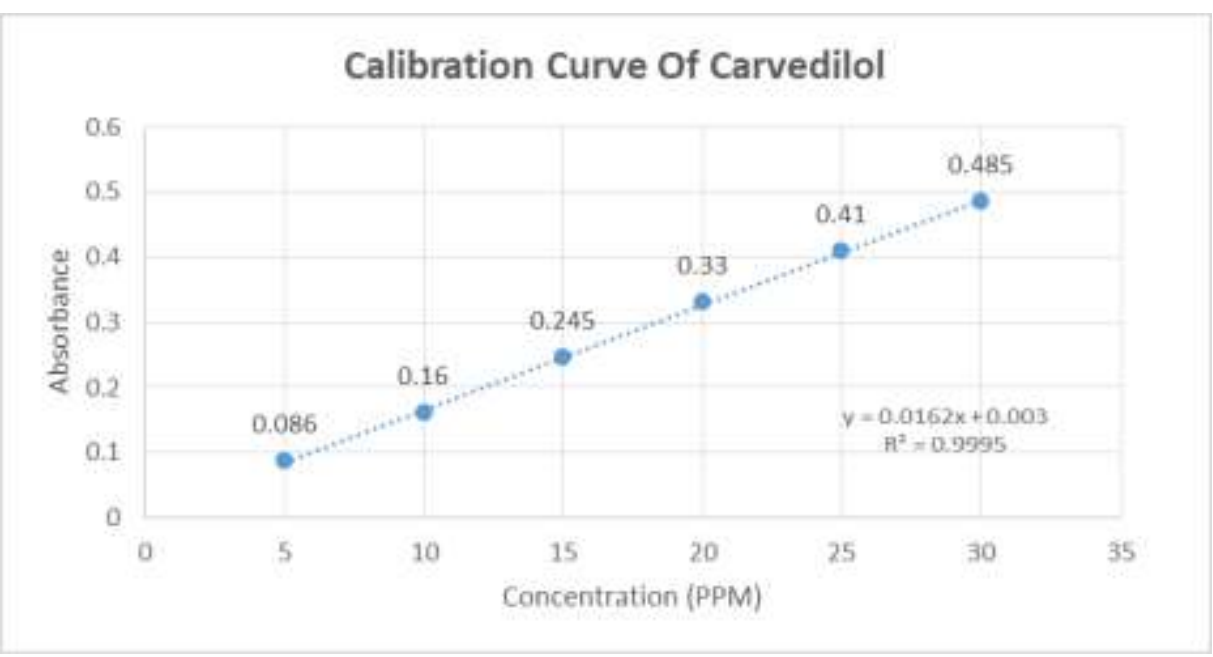

Figure 1 Calibration curve of carvedilol

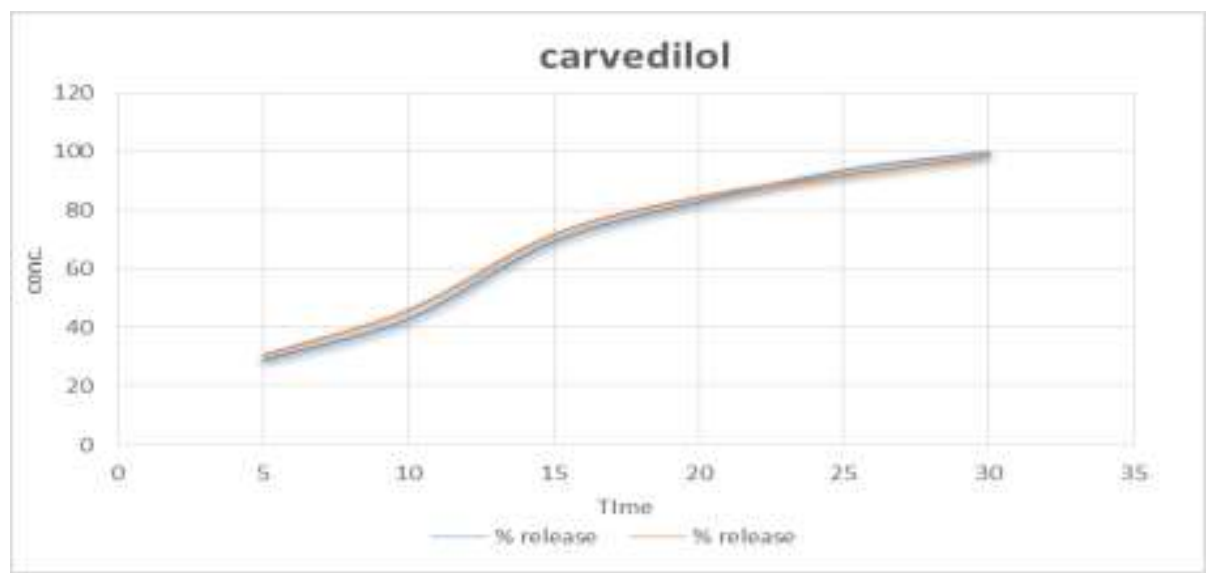

Figure 2 Percent (\%) release of carvedilol 


\section{Result and Calculations}

Table 3 Weight of Tablets [Milligram (mg)]

\begin{tabular}{|c|c|c|}
\hline Sr. No. & Brand A & Brand B \\
\hline 1 & 114 & 121 \\
\hline 2 & 113 & 122 \\
\hline 3 & 114 & 123 \\
\hline 4 & 114 & 123 \\
\hline 5 & 114 & 121 \\
\hline 6 & 116 & 122 \\
\hline 7 & 113 & 121 \\
\hline 8 & 114 & 122 \\
\hline 9 & 114 & 122 \\
\hline 10 & 114 & 123 \\
\hline 11 & 115 & 122 \\
\hline 12 & 113 & 122 \\
\hline 13 & 114 & 123 \\
\hline 14 & 116 & 121 \\
\hline 15 & 114 & 122 \\
\hline 16 & 113 & 122 \\
\hline 17 & 114 & 123 \\
\hline 18 & 114 & 122 \\
\hline 19 & 113 & 122 \\
\hline 20 & 114 & 121 \\
\hline Total & $2280 \mathrm{mg}$ & $2440 \mathrm{mg}$ \\
\hline
\end{tabular}

Average weight of tablets: Brand A=114 mg, Brand B= $122 \mathrm{mg}$.

Weight Variation of Brand A:

$$
\% \text { weight variation }=\frac{\text { weight of each tablet }- \text { average weight of tablets }}{\text { Average weight of tablets }} \times 100
$$

Table 4 Percent weight variation of brand A

\begin{tabular}{|c|c|c|}
\hline Sr. No. & Weight of tablet (mg) & \% weight variation \\
\hline 1 & 114 & 0 \\
\hline 2 & 113 & -0.877 \\
\hline 3 & 114 & 0 \\
\hline 4 & 114 & 0 \\
\hline 5 & 114 & 0 \\
\hline 6 & 116 & 1.75 \\
\hline 7 & 113 & -0.877 \\
\hline 8 & 114 & 0 \\
\hline 9 & 114 & 0 \\
\hline 10 & 114 & 0 \\
\hline 11 & 115 & 0.877 \\
\hline
\end{tabular}




\begin{tabular}{|c|c|c|}
\hline 12 & 113 & -0.877 \\
\hline 13 & 114 & 0 \\
\hline 14 & 116 & 1.75 \\
\hline 15 & 114 & 0 \\
\hline 16 & 113 & -0.877 \\
\hline 17 & 114 & 0 \\
\hline 18 & 114 & 0 \\
\hline 19 & 113 & -0.877 \\
\hline 20 & 114 & 0 \\
\hline
\end{tabular}

Weight Variation of Brand B:

$$
\% \text { weight variation }=\frac{\text { weight of each tablet }- \text { average weight of tablets }}{\text { Average weight of tablets }} \times 100
$$

Table 5 Percent weight variation of brand B

\begin{tabular}{|c|c|c|}
\hline Sr. No. & Weight of tablet (mg) & \% weight variation (\%) \\
\hline 1 & 121 & -0.8197 \\
\hline 2 & 122 & 0 \\
\hline 3 & 123 & 0.8197 \\
\hline 4 & 123 & 0.8197 \\
\hline 5 & 121 & -0.8197 \\
\hline 6 & 122 & 0 \\
\hline 7 & 121 & -0.8197 \\
\hline 8 & 122 & 0 \\
\hline 9 & 122 & 0 \\
\hline 10 & 123 & 0.8197 \\
\hline 11 & 122 & 0 \\
\hline 12 & 122 & 0 \\
\hline 13 & 123 & 0.8197 \\
\hline 14 & 121 & -0.8197 \\
\hline 15 & 122 & 0 \\
\hline 16 & 122 & 0 \\
\hline 17 & 123 & 0.8197 \\
\hline 18 & 122 & 0 \\
\hline 19 & 122 & 0 \\
\hline 20 & 121 & -0.8197 \\
\hline & & \\
\hline
\end{tabular}

\subsection{Friability Test}

Brand A: Initial wt. (W $\left.\mathrm{W}_{1}\right): 2.28 \mathrm{gm}$, Final wt. $\left(\mathrm{W}_{2}\right): 2.275 \mathrm{gm}$

$$
\% \text { Friability }=\frac{W_{1}-W_{2}}{W_{1}} \times 100
$$




$$
\begin{gathered}
\% \text { Friability }=\frac{2.280-2.275}{W_{1} 2.280} \times 100 \\
\% \text { Friability }==0.219 \%
\end{gathered}
$$

Brand B: Initial wt. (W1): 2.440 gm, Final wt. (W2): 2.434 gm

$$
\begin{gathered}
\% \text { Friability }=\frac{W_{1}-W_{2}}{W_{1}} \times 100 \\
\% \text { Friability }=\frac{2.440-2.434}{2.440} \times 100 \\
\% \text { Friability }=0.25 \%
\end{gathered}
$$

\subsection{Hardness Test}

Table 6 Hardness test parameter for brand A

\begin{tabular}{|c|c|}
\hline Sr. No. & Hardness $\left.\mathbf{( k g} / \mathbf{c m}^{2}\right)$ \\
\hline 1 & 5.2 \\
\hline 2 & 5 \\
\hline 3 & 4.9 \\
\hline 4 & 4.8 \\
\hline 5 & 5.1 \\
\hline Average Hardness & $25 / 5=5 \mathrm{~kg} / \mathrm{cm}^{2}$ \\
\hline
\end{tabular}

Table 7 Hardness test parameter for brand B

\begin{tabular}{|l|l|}
\hline Sr. No. & Hardness $\mathbf{( k g} / \mathbf{c m}^{2} \mathbf{~}$ \\
\hline 1 & 5.4 \\
\hline 2 & 4.9 \\
\hline 3 & 5.1 \\
\hline 4 & 5 \\
\hline 5 & 4.9 \\
\hline Average Hardness & $25.3 / 5=5.06 \mathrm{~kg} / \mathrm{cm}^{2}$ \\
\hline
\end{tabular}

Table 8 Comparative results of both brands

\begin{tabular}{|c|c|c|}
\hline Parameter & Brand A & Brand B \\
\hline Colour & White & Sunset Yellow \\
\hline Weight Variation & \pm 7.5 & \pm 7.5 \\
\hline Friability & $0.219 \%$ & $0.25 \%$ \\
\hline Hardness & $5 \mathrm{~kg} / \mathrm{cm}^{2}$ & $5.06 \mathrm{~kg} / \mathrm{cm}^{2}$ \\
\hline Disintegration Time & $14 \mathrm{~min}$ & $15 \mathrm{~min}$ \\
\hline \% Release & $99.97 \%$ & $98.8 \%$ \\
\hline
\end{tabular}




\section{Conclusion}

Carvedilol is well known anti-hypertensive drug also commonly used for heart patients. Any formulation quality and efficiency depend on their evaluation parameter and their specification. Evaluated carvedilol brands shows result under specification which based on standard values. Weight variation and friability both shows result as per specification or standard value which given in Indian Pharmacopeia. But little variation seen in hardness, disintegration time, dissolution time during the test procedure. These parameters are passed all parameters as per pharmacopeia.

\section{Compliance with ethical standards}

\section{Acknowledgments}

We thank our lab technician and other helpers who made this study possible.

\section{Disclosure of conflict of interest}

The authors declare that there is no conflict of interest.

\section{References}

[1] Gastone Leonetti, Colin G. Egan. Use of Carvedilol in hypertension: an update. Vascular Health and Risk Management. 2012; 8: 307-322.

[2] Shashank Singh. Charles Preust. Carvedilol. Statpearls Content JS King. 2021.

[3] James J. Dinicolantonio, Hassan Fares, Asfandyar K. Niazi, Saurav Chatterjee, et.al. Cardiac Risk Factors and Prevention Review Beta Blocker in Hypertension, Diabetes, Heart Failure and Acute Myocardial Infraction: A Review of the Literature. Openheart. 2015; 2(1): 000230.

[4] Satish Maharaj, Karan Seegobin, Pramod Reddy, et.al. Severe carvedilol toxicity with overdose caution in cirrhosis.Clinical Hypertension. 2017; 23(25): 1-5.

[5] Hiroki Watanabe, Neiko Ozala, Takeshi Morimoto, Bao Bingyuan, et.al. Long term use of carvedilol in patients with ST-segment elevation myocardial infraction treated with primary percutaneous coronary intervention. Plos One. Aug 2018; 13(8): 1-17.

[6] Saleem M, Shahin M, Srinivas B, Begum A. Evaluation of tablets by friability apparatus. IJRPC. 2014; 4(4): 837840 .

[7] L. Lachman, HA Liberman, JL Kanig. The Theory and Practice of Industrial Pharmacy. Varghese Publishing House, 3rd Edition: 293.

[8] Loyd V. Allen, Jr. Howard C. Ansel. Ansel's Pharmaceutical Dosage Forms and Drug Delivery Systems. Wolters Kluwer publication, 10th edition. 263, 271, 272.

[10] Indian Pharmacopoeia. Government of India, Ministry of Health \& Family Welfare, Controller of Publication, 8th edition. 2018: 1: 387, 313, 507.

[11] ME Aulton, K MG Tylor. The Design and Manufacturing Medicines. Aultons Pharmaceutics, Elsevier Publication, 4th Edition: 504.

[12] Indian Pharmacopoeia. Government of India, Ministry of Health \& Family Welfare, Controller of Publication, fourth Edition. 1996: 2: A144-A145.

[13] Shah VP, Konecny JJ, Everett RL, McCullough B, Noorizadeh AC, Skelly JP. In Vitro Dissolution Profile of Water Insoluble Drug Dosage Forms in the Presence of Surfactants Pharm. Res. 1989; 6: 612-618.

[14] Remington. Essential of Pharmaceutics. Published by Pharmaceutical Press, 1st Edition. 63.

[15] Craig DQM. The mechanism of drug release from solid dispersion in water-soluble polymers. Int. J.Pharm. 2002; 231: 131-144.

[9] Hari Babu R, Nagu Raju R. Development of dissolution medium for Carvedilol tablets. J. Pharm, Res. 2009; 2: 931933. 